\title{
REMOTE SURVEILLANCE OF SHELL STRUCTURE LOAD-BEARING CAPACITY
}

\author{
Leonid Yulianovich Stupishin* \\ Southwest State University, Kursk, Russia \\ Alexandr Vasilyevich Masalov \\ Southwest State University, Kursk, Russia \\ Feodor Altukhov \\ Southwest State University, Kursk, Russia
}

The problem background of load-bearing capacity remote surveillance was presented. The issues of continuous automatic surveillance of building and structure condition arrangement are discussed in the article. Principles and basic approaches to surveillance arrangement are considered in the context of solving the problem for Kursk State Circus building reconstruction, which was damaged by fire and environmental impacts occurred after several year of being in no operation. Surveillance parameters - displacement, relative humidity, temperature, heat flow and means of measurement are discussed The automated system for building surveillance, maintenance and data storage is considered. Load-bearing capacity remote surveillance should be the essential part of this automated system.

Key words: Remote surveillance of structure conditions, Dome, Automated control system, Visual monitoring, Instrumental monitoring

\section{INTRODUCTION}

Among spatial load-bearing structures of building, shells are the most economical and efficient bearing structures but, on the other hand, they are also the most dangerous load-bearing members, which require special attention. As the recent failures of Aqua-park and Bauman Market buildings in Moscow, the accidents in Poland and Germany in the winter of 2006, the collapse of the structure of the shopping and entertainment center in St. Petersburg (2010) show the lack of the proper monitoring of structural condition causes not only huge material losses but also losses of human lives.

In the Russian Federation, there are regulations, which define the time of regular buildings and structures inspections [1-6]. The experts of the enterprises managing these buildings and structures carry out their own monitoring of structure conditions. They often lack the experience and knowledge necessary to assess properly and promptly possible dangerous situations caused by load-bearing structures condition.

Usually, when specialized organizations inspect a building, they record information concerning the current structural condition but the data of previous inspections may be lost or focused on the aspects that do not help to create a complete picture of defect development in a period of time. Finally, when inspecting spatial shell systems experts are required to work at a significant height, in hard-to-get-at places, etc., there is a need for special access equipment, additional expenses, and, in some cases, it is even impossible to provide an access because of the operation conditions.

To analyze the current stress-strain state of a structure, it is necessary to fix the movements of the design points and the calculation analysis technique, which allows estimating the residual life of the structure [07-10].

Thus continuous remote surveillance of spatial building structures using modern instrumental devices and computers is necessary. It will allow not only to record the data but also to track changes of measured parameter during a time and to analyze the actual structural condition.

\section{AIMS OF SURVEILLANCE}

Nowadays in many developed countries operates hundreds of expert systems which work in various spheres of construction: in design of civil 
and industrial objects of construction, in organizational and technological preparing and control in construction, in civil and industrial objects surveillance.

Expert systems could allow conducting inspections of construction objects. They collect and systematize information required. This information will allow estimating level of obsolescence and deterioration of bearing and enclosing structures. On the mathematical modeling base expert systems predict values of obsolescence and deterioration and to determine residual terms of reliable operation of structures.

The principal task of expert systems is to allow every user to get all information he needs to make a work that usually perform high-qualified specialists when estimating structure and building conditions, to optimize structure maintenance technologies, and to help in making decisions in the area of maintenance, repair and reconstruction of structures and buildings.

General aim of construction object surveillance is regular long-term monitoring of permanent and temporarily loads deflections, deformations and forces occurring in structures. Monitoring system should provide surveillance of forces and stresses in most loaded cross-sections of structures with the purpose of existing stress-strain condition determination and comparing with design values. Preemptively locate critical and prefault conditions and perform measurements of foundation settings.
Surveillance system assumes various types of sensors installed on members of structures to determine physical (moisture ant temperature) and force (static and dynamic loading) impacts on structure strength and deformability. Sensors of deformation, temperature, displacement, inclination transfer their data in digital form to computer by wire- free interface.

The main directions of spatial structures remote surveillance include follows. Spatial structure position monitoring; structural geometry and mutual position monitoring; structural shape monitoring; structural deformation monitoring; structural defects and their behaviour monitoring (e.g. crack width and length, change of cracks size and shape, etc.). Loading conditions monitoring; deformation conditions monitoring, humidity, environmental hazards monitoring, etc.).

The part of remote monitoring, relate to visual monitoring, allows to carry out continuous control of bearing capacity of a building or structure on the basis of the external signs of deterioration. It is obvious that a continuous remote visual control is carried out in accordance with the instructions of the specialized expert organization in a few strictly defined places, which allow to make a conclusion on the behavior of a structure. Structural deformation monitoring also allows to assess the residual life of structural strength and the possibility of its further operation. This surveillance data allows to adjust structural model of a building or structure in operation.

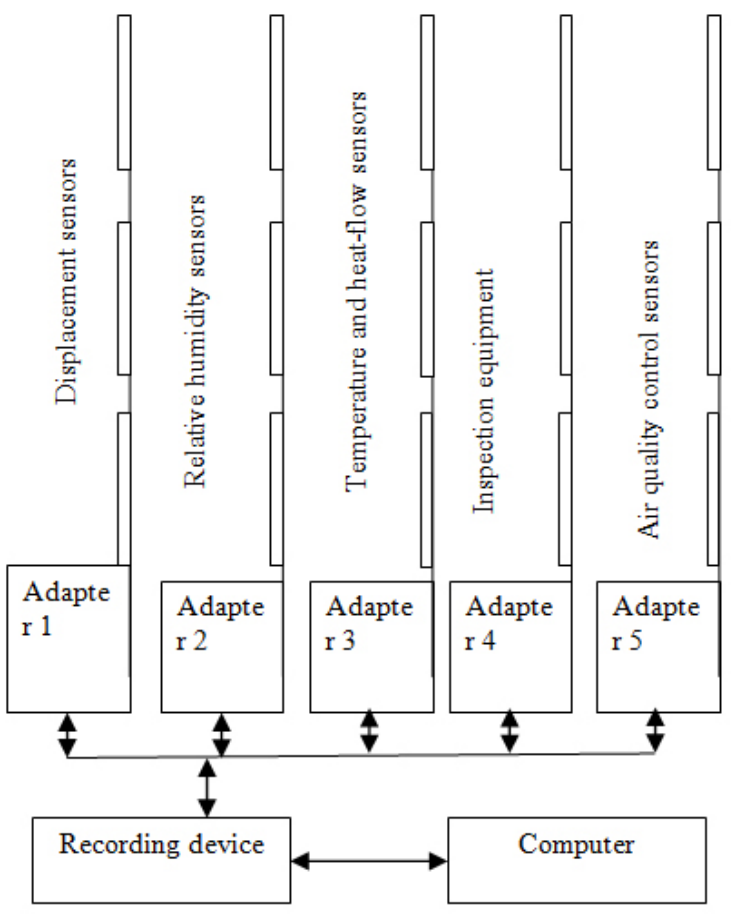

Figure 1: A flow chart of a measuring system for remote monitoring of a building structure condition 
Thus, it is possible to distinguish three main components of the surveillance of buildings and structures bearing capacity:

- visual monitoring using cameras and other equipment which allows recording structural condition in time and processing the obtained data on a computer;

- remote instrumental monitoring which allows recording the specified parameters characterizing structural condition;

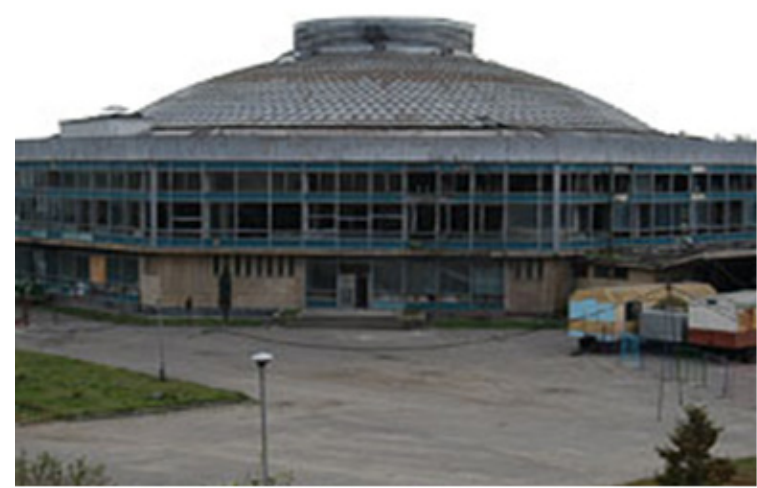

Figure 2: Kursk state circus building under reconstruction and after reconstruction

\section{THE OBJECT OF SURVEILLANCE}

The developed method will be proposed for the continuous remote surveillance of the dome over the Kursk State Circus building. The fire caused great damage to the circus building in December 1996 and since then it has not been in operation (Figure 2). Currently, the building structure accumulated damages caused by the operation and also got in the period when the building was not in operation, Figure 3. During building renovation and reconstruction, were taken measures to eliminate the damages and strengthen the structure.

The circus building had 2000 seats. It was built in the period of 1969- 1971 according to the standard building type 264-11-1 taking into account local conditions by the project organization "Kurskgrazhdanproekt". The building includes office and service block, arena and spectacular premises having a regular octagon shape with a precast reinforced concrete shallow shell with a diameter of $43.5 \mathrm{~m}$ and a height of $6 \mathrm{~m}$ according to the design. The height of the arena and threestoried spectacular premises of the building (hereinafter referred to as the building) is 21.8 $\mathrm{m}$, the largest lateral dimension on the extreme

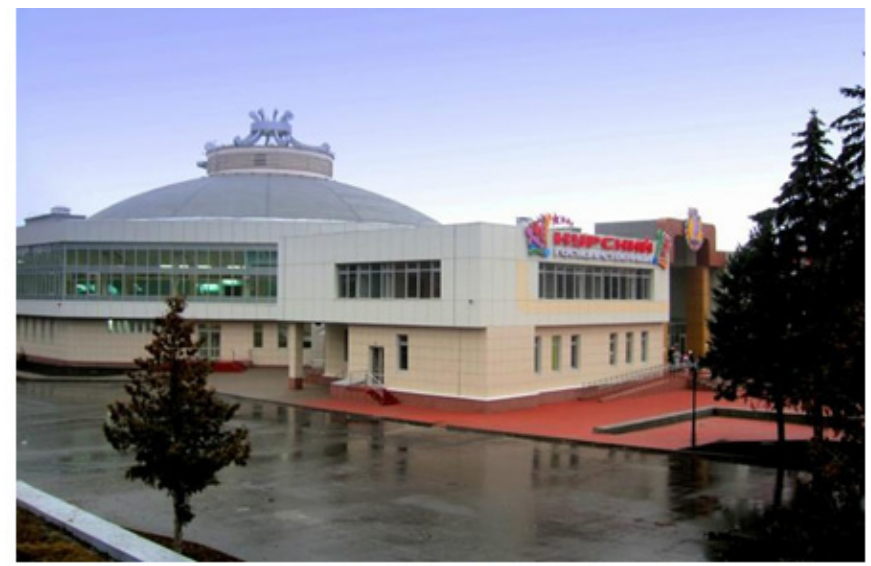

- analysis and synthesis of structural model in order to determine the residual life of structural strength and operation capacity based on the obtained data.

Figure 1 shows a flow chart of a measuring system for remote monitoring of a building structural condition. Taking into account rather high costs of periodic inspections, as well as the involved machinery and equipment, the proposed system will be cost-effective with regard to a sufficiently long operation life of buildings and structures.

axes is $55.5 \mathrm{~m}$, there are basement rooms for technical and illusionist equipment. The building has a pile foundation.

When carrying out surveillance it is expedient to combine the direct monitoring surveillance (periodic engineering condition inspection) and remote surveillance. These types of surveillance have their advantages and disadvantages. The use of both these methods allows getting the most complete and timely information on technical state of structures.

The structural model of the building with a dome, taking into account its damages and defects (if any, shall be prepared at the first stage. After making calculations, it is necessary to identify the locations of the unsafe cross-sections, where the strength of the shell will be analyzed continually, and the locations of the visual and instrumental monitoring devices. 

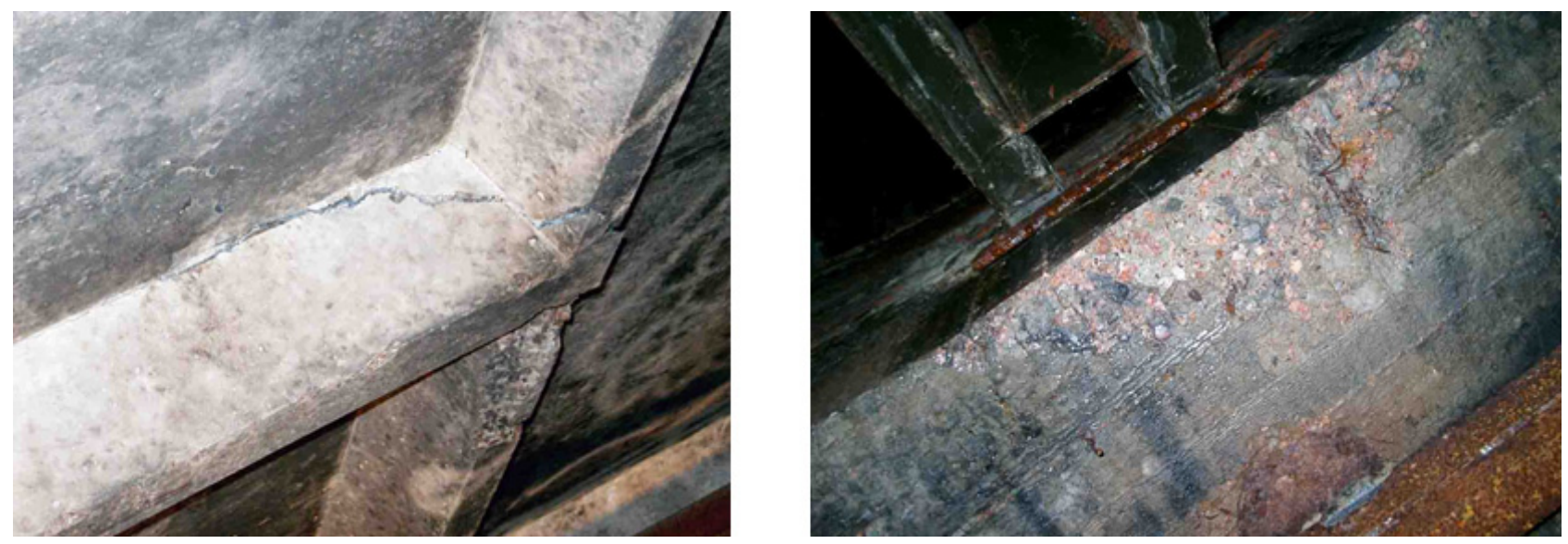

Figure 3: Inclined crack in the reinforced-concrete rib (left) and peeling of concrete on the top support ring caused by fire (right)
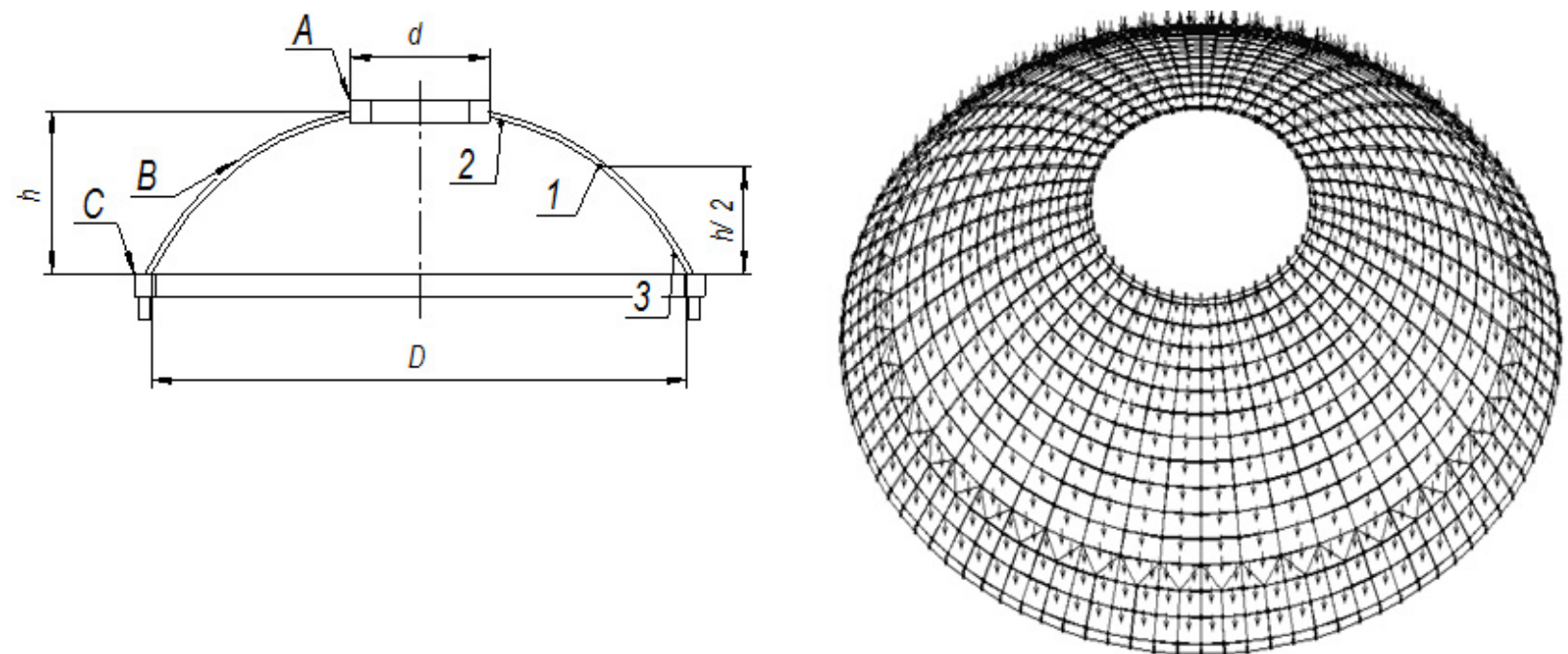

Figure 4: The scheme of the shallow shell dome and finite element dome model with the load distributed on the shell surface

$A$ is the top ring of the shallow shell; $B$ is the shell surface; $C$ is the bottom support ring of the shell; $\mathrm{D}, \mathrm{d}$ are the diameters of the top and bottom shell rings; $h$ is the shell height. For the dome structure digital analysis the finite element model was developed (Figure 4).

The position of visual monitoring devices shall allow recording of the top and the bottom support rings displacements. In the case of symmetrical load action, the instrumental monitoring devices shall be installed at points 1,2, 3, as shown in Figure 4. It is necessary to remember that the position of these points depends strongly on the ratio of the diameters $\mathrm{D} / \mathrm{d}$ and the shell height.

Currently, there are measuring systems consisting of displacement sensors, relative humidity sensors, temperature and heat flow sensors, air quality control sensors, etc., and recording devices such as multi-channel universal recorder "Terem - 4" manufactured by RPC "Interpribor".
Connection of the measuring system to a computer allows computerizing the collection and storage of the information on the of bearing and shell structures conditions.

Displacement sensors allow monitoring the growth of cracks, deflections and stresses in the structure. Relative humidity, temperature, and heat flow sensors allows to monitor the structural temperature and humidity conditions in hard-to-get-at places, to identify the places of high humidity because of leaks or moisture condensation, the places of the thermal protection failure of the enclosure structure. Moreover, other sensors monitor the parameters, which are not related directly to the state of load-bearing structures, such as smoke detector sensors and gas analyzers can be connected to a universal recorder. 


\section{AUTOMATED SYSTEM FOR BUILDING SURVEILLANCE, MAINTENANCE AND DATA STORAGE}

For accumulation, storage and processing of surveillance data should be used also special automated systems. Nowadays are being developed and implemented various automated systems of building maintenance [11]. Those automated system should include data about construction, operating, surveillance of a building or structure.

The aims of such system are:

- creating of conditions for accumulation, storage, updating of authentic information about buildings, structures and urban area development;

- enabling an opportunity to control and processing of object data and it's components (elements, structures, premises, equipment, land plots, etc.;

- enabling of data exchange and support of the automated systems of control and safety ensuring of buildings and structures.

\section{The tasks of such system are:}

- accumulation and storage of data about object and also law information and codes for construction, quality control at the stages of construction and operating, surveillance and maintenance of buildings, structures and urban area development;

- control and processing of data about an object and its components;

- data preparing for conducting of inspections, repairing and reconstruction;

- management of documentation;

- data preparing for reconstruction design, repairing, cost estimation;

- surveillance of operating buildings, structures and equipment;

- information supply for building control systems and dispatcher systems.

The results of tusk realization are: system organization of object exportation, reducing of maintenance costs, safety level increase when object operation, ensuring and improving of quality of object and equipment.

The system has flexible structure for control and creating of subsections in the form of a tree. User himself can plan quantity of sections and subsections in which will be stored and processed object data. It is possible to move from one section to another as moving along the tree as specifying a path in special window. It is possible to move by links which were in text put or drawings in different sections.

At the Figure 5 the variant of system is presented which contains following sections: "Design documentation"', "Building (premise) certificate", "Technological equipment", "Inspections", "Control systems for building and equipment".

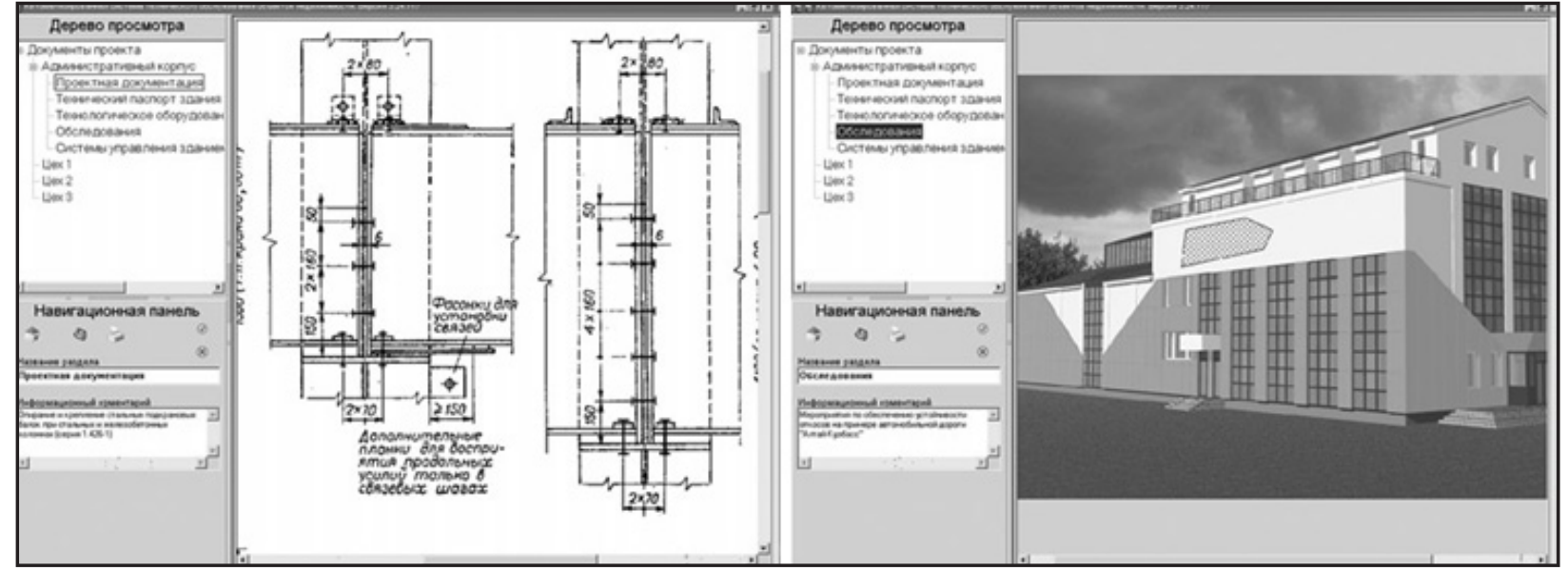

Figure 5: System's window example

In the first section design documentation is presented, this and every other section could contain an information in form of texts, pictures or drawings. The second section contains data about technical parameters of building and it's premises in including their energy efficiency pa- rameters. In the third section is presented data about technological equipment installed in premises of building. An information about influence of the equipment on structures is presented. The fifth section contains information about dispatcher control of the building systems. 
In the example of system structure the following subsections are included: "Architectural and construction drawings", "Construction drawings, including loads", "Plumbing equipment", "Ventilation and air conditioning systems", "Electricity supply systems", "Systems of communication, guarding and fire signalization" ,etc.

\section{CONCLUSION}

We consider that after the renovation and reconstruction, the Kursk circus building needs for both periodic direct inspections and remote monitoring of the building bearing and enclosing structures taking into account the importance of this building for the city.

To ensure safe operation of buildings exposed to non-project impacts, it is necessary to conduct continuous monitoring of their condition. Remote measurement of stresses and displacements of bearing structures will allow us to make conclusions about the possibility of further safe operation of the building.

For data transfer from measuring instruments to computer, processing and storing data and are accessible for the expert place, you need to use wireless data transmission technology.

Data processing must be carried out with the help of automated processing systems and storage, similar to that described in [11].

\section{REFERENCES}

1) Federal law \# 384 (2009) About safety of buildings and structures

2) Governing document 22-01.97 (1997) Requirements to safeness estimation conducting of supervised industrial enterprises and objects

3) Code of rules 13-102-2003 (2003) Rules of bearing structures inspection in buildings and constructions

4) National standard 57778-2010 (2010) 2008 Technical recommendations 182-08 (2008) Technical recommendations to scientific and technical support and monitoring of largespan, high-rise and other unique buildings and constructions

5) Moscow working document in construction 02-08 (2008) Structures of buildings and constructions, including large-span, high-rise and unique manual for scientific and technical support and monitoring
6) Stupishin, L. and Kolesnikov, (2014), Geometric Nonlinear Orthotropic Shallow Shells Investigation A., Appl. Mech. and Mat., Vol. 501-504, pp.766-769.

7) Stupishin, L. and Kolesnikov A. (2014), Geometric Non-linear Shallow Shells for Variable Thickness , Adv. Mat. Res. Vol. 919-921, pp. 144-147

8) Stupishin, L. and Kolesnikov A. (2014). Reconstruction of Shallow Shells for increase Bearing Capacities and Operating, Appl. Mech. and Mat. Vol. 580-583, pp.3062-3065

9) Stupishin, L. and Nikitin, K. (2014). Mixed finite element of geometrically nonlinear shallow shells of revolution, Applied Mechanics and Materials Appl. Mech. and Mat. Vol.501504, pp514-517

10) Stupishin, L. and Puchnin, S. (2012), Automated System of Control, Storage and Processing of Data on Buildings, Structures and Urban Area Development, South-West State University Proc., Vol.4, pp.21-23

Paper sent to revision: 22.07.2017.

Paper ready for publication: 01.09.2017. 